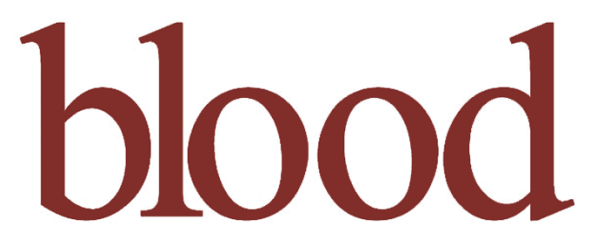

2007 109: 3300-3307

Prepublished online Dec 19, 2006;

doi:10.1182/blood-2006-06-028001

\title{
Selective deletion of antigen-specific CD8+ T cells by MHC class I tetramers coupled to the type I ribosome-inactivating protein saporin
}

Paul R. Hess, Carie Barnes, Matthew D. Woolard, Michael D. L. Johnson, John M. Cullen, Edward J. Collins and Jeffrey A. Frelinger

Updated information and services can be found at:

http://bloodjournal.hematologylibrary.org/cgi/content/full/109/8/3300

Information about reproducing this article in parts or in its entirety may be found online at:

http://bloodjournal.hematologylibrary.org/misc/rights.dtl\#repub_requests

Information about ordering reprints may be found online at:

http://bloodjournal.hematologylibrary.org/misc/rights.dtl\#reprints

Information about subscriptions and ASH membership may be found online at:

http://bloodjournal.hematologylibrary.org/subscriptions/index.dtl

Blood (print ISSN 0006-4971, online ISSN 1528-0020), is published semimonthly by the American Society of Hematology, $1900 \mathrm{M} \mathrm{St}$, NW, Suite 200, Washington DC 20036.

Copyright 2007 by The American Society of Hematology; all rights reserved.

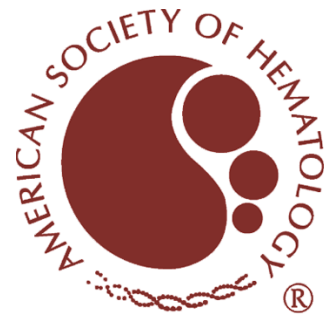




\title{
Selective deletion of antigen-specific $\mathrm{CD} 8^{+} \mathrm{T}$ cells by MHC class I tetramers coupled to the type I ribosome-inactivating protein saporin
}

\author{
Paul R. Hess, ${ }^{1,2}$ Carie Barnes, ${ }^{1}$ Matthew D. Woolard, ${ }^{1}$ Michael D. L. Johnson, ${ }^{1}$ John M. Cullen, ${ }^{3}$ Edward J. Collins, ${ }^{1}$ \\ and Jeffrey A. Frelinger ${ }^{1}$ \\ ${ }^{1}$ Department of Microbiology and Immunology, University of North Carolina, Chapel Hill; ${ }^{2}$ Department of Clinical Sciences, College of Veterinary Medicine, \\ North Carolina State University, Raleigh; and ${ }^{3}$ Department of Population Health and Pathobiology, College of Veterinary Medicine, \\ North Carolina State University, Raleigh
}

CD8 ${ }^{+}$cytotoxic T lymphocytes (CTLs) are important effector cells responsible for tissue destruction in several autoimmune and allograft-related diseases. To discover if pathogenic T cells could be selectively deleted, we investigated the ability of a toxin coupled to major histocompatibility complex (MHC) class I tetramers to kill antigen-specific $\mathrm{CD}^{+} \mathrm{T}$ cells. H2- $\mathrm{D}^{\mathrm{b}}$ tetramers were assembled using strepta- vidin conjugated to the ribosome-inactivating protein (RIP) saporin (SAP). These tetramers inhibited ribosome activity in vitro, retained the T-cell receptor (TCR)binding specificity of their nontoxic counterparts, and were internalized by $100 \%$ of target cells, leading to cell death in 72 hours. Cytotoxicity was dependent on the tetramer dose and avidity for the T cell. A single injection of the SAP-coupled tet- ramer eliminated more than $75 \%$ of cognate, but not control, $T$ cells. This work demonstrates the therapeutic potential of cytotoxic tetramers to selectively eradicate pathogenic clonotypes while leaving overall T-cell immunity intact. (Blood. 2007;109:3300-3307)

(C) 2007 by The American Society of Hematology

\section{Introduction}

Autoimmune diseases such as type 1 diabetes mellitus and multiple sclerosis result from chronic organ-specific damage mediated by autoreactive $\mathrm{T}$ cells. Ideally, treatment of these conditions would prevent or disable the inciting mechanisms, but at present, the underlying causes remain unknown. Even if available, such therapy likely would be inadequate for treating clinical disease because once initiated, autoaggressive T-cell responses can be selfperpetuating, ${ }^{1}$ and an efficient means of halting ongoing immune attack will also be needed for successful treatment.

In analogous fashion, normal T-cell activity can have pathologic consequences in allotransplantation settings, leading to graft rejection, or in bone marrow recipients, to acute or chronic graft-versushost disease. Prevention or treatment of injurious T-cell responses in transplantation patients with nonspecific immunosuppressive agents, such as glucocorticoids, calcineurin inhibitors, or antimetabolites, is variably successful, requires long-term administration, and poses risks of toxicity, infection, and malignancy. ${ }^{2-8}$ In T-cell-mediated autoimmune diseases, significant improvements in outcome with these drugs have not been reported; hence, given the hazards, their use is not advocated. ${ }^{9,10}$

There is increasing evidence that $\mathrm{CD} 8^{+} \mathrm{T}$ cells are the important mediators of tissue destruction in type 1 diabetes mellitus ${ }^{11-13}$ and multiple sclerosis; ${ }^{14-16}$ therefore, selective deletion of pathogenic cytotoxic T lymphocyte (CTL) clonotypes might constitute an effective treatment. Similarly, elimination of graft- or host-reactive $\mathrm{CD}^{+}$T-cell populations could prevent complications associated with allotransplantation. T-cell clones are distinguished by their unique surface T-cell receptors (TCRs), which bind to a particular peptide-major histocompatibility complex (pMHC) molecule com- bination. Specific $\mathrm{CD} 8^{+} \mathrm{T}$ cells in mixed populations can therefore be identified with fluorophore-labeled, soluble tetrameric complexes of pMHC class I molecules (tetramers). ${ }^{17}$ In addition to marking particular clonotypes, tetramer-TCR interactions mimic binding of native ligands, leading to intracellular signaling, activation, differentiation, and proliferation. ${ }^{18}$ Previously, we have shown that a single injection of tetramer primes $\mathrm{T}$ cells in vivo, while repetitive administration has a tolerizing effect on alloreactivity. ${ }^{19,20}$

The ability to modulate specific $\mathrm{CD} 8^{+} \mathrm{T}$-cell activity in vivo suggested that tetramers might be a useful therapeutic approach for targeting pathogenic $\mathrm{T}$ cells. We reasoned that tetramer-mediated delivery of a cytotoxic molecule would result in selective T-cell deletion. To test this possibility, we produced $\mathrm{H} 2-\mathrm{D}^{\mathrm{b}}$ tetramers coupled to saporin (SAP), a potent type I ribosome-inactivating protein (RIP). Construction of a radioactive tetramer for killing $\mathrm{CD}^{+} \mathrm{T}$ cells was recently described. ${ }^{21}$ Here we show that a SAP-coupled tetramer specifically binds and is internalized by the cognate $\mathrm{T}$ cell, resulting in cell death by 72 hours. We also demonstrate that a single injection of a SAP-coupled tetramer was capable of eliminating more than $75 \%$ of target T cells in vivo.

\section{Materials and methods}

\section{Mice}

C57BL/6J mice were obtained from The Jackson Laboratory (Bar Harbor, ME). TCR-transgenic B6.D2 TgN(Tcr-Lcmv)327Sdz/Fre mice (designated as P14), and $\mathrm{B} 6 \operatorname{TgN}(\operatorname{Tcr}-H Y)$ mice that had been backcrossed to C57BL/6J-rag- $1^{t m l}$ recombinase-deficient mice (designated as $\mathrm{H}-\mathrm{Y}$ ), were
Submitted June 8, 2006; accepted December 12, 2006. Prepublished online as Blood First Edition Paper, December 19, 2006; DOI 10.1182/blood2006-06-028001.

The publication costs of this article were defrayed in part by page charge payment. Therefore, and solely to indicate this fact, this article is hereby marked "advertisement" in accordance with 18 USC section 1734. 
bred in-house, as described previously. ${ }^{18}$ P14 mice were crossed with C57BL/6- $\mathrm{Tg}\left(H 2 \mathrm{~K}^{b}-\mathrm{GFP}\right) /$ Fre mice that express green fluorescent protein (GFP) under control of the $\mathrm{H} 2-\mathrm{K}^{\mathrm{b}}$ promoter $^{22}$ to produce P14.GFP mice. ${ }^{23}$ All transgenic mice were phenotyped by flow cytometry of peripheral blood $\mathrm{T}$ cells. Mice were housed in a specific pathogen-free laboratory animal facility that is accredited by the Association for Assessment and Accreditation of Laboratory Animal Care (AAALAC), and typically were used in experiments at 6 to 8 weeks of age. Experimental procedures were reviewed and approved by the University of North Carolina-Chapel Hill (UNC-CH) Institutional Animal Care and Use Committee (IACUC), and adhered to published principles of laboratory animal care.

\section{Preparation of peptides and tetramers}

The H2- $\mathrm{D}^{\mathrm{b}}-$ restricted peptide epitopes flu (ASNENMETM) and gp33 (KAVYNFATC), the gp33 altered peptide ligands (APLs) C9M and K1S, and the H-Y APL C2A (KASRNRQYL) were synthesized at the UNC-CH Peptide Synthesis Facility, purified by reversed-phase high-pressure liquid chromatography, and dissolved in dimethyl sulfoxide at $10 \mathrm{mg} / \mathrm{mL}$. Murine $\mathrm{H} 2-\mathrm{D}^{\mathrm{b}}$ monomers were produced by folding recombinant $\alpha$-chains purified from Escherichia coli inclusion bodies with $\beta_{2}$ microglobulin and synthetic peptide. Preparation of the mutated D227K H2-D molecule was described previously. ${ }^{24}$ Following biotinylation with BirA enzyme and size exclusion purification, tetramers were generated from pMHC monomers by stepwise addition (one-fourth total every 10 minutes) of unlabeled or phycoerythrin (PE)-conjugated avidin (Ultravidin; Leinco Technologies, St Louis, MO), or streptavidin (SA)-SAP (Advanced Targeting Systems, San Diego, CA) to a final 1:5 (avidin/pMHC) molar ratio. The SA-SAP reagent contained an average of 2.5 moles of SAP per mole of SA. The potency of SAP conjugates was determined by an in vitro translation inhibition assay performed by Advanced Targeting Systems. Briefly, diluted SAP-containing samples (or phosphatebuffered saline [PBS] control) were incubated with luciferase mRNA, an amino acid mixture, and nuclease-treated rabbit reticulocyte lysate for 1 hour at $30^{\circ} \mathrm{C}$. After chilling on ice to halt protein synthesis, the translation mixture was added to a luciferase assay reagent (Promega, Madison, WI), and emitted light was measured with a luminometer, in triplicate, and expressed as a percentage of control values.

\section{Purification of $\mathrm{CD}^{+} \mathrm{T}$ cells}

Spleens from donor mice were aseptically collected in PBS containing $0.5 \%$ fetal bovine serum (FBS), disaggregated, and depleted of erythrocytes using ammonium chloride lysis buffer $\left(0.15 \mathrm{M} \mathrm{NH}_{4} \mathrm{Cl}_{4}, 1 \mathrm{mM} \mathrm{KHCO} 3\right.$, and $0.1 \mathrm{mM} \mathrm{Na} 2$ EDTA). Splenocytes were enriched for $\mathrm{CD}^{+} \mathrm{T}$ cells by negative selection using a $\mathrm{CD}^{+}{ }^{+} \mathrm{T}$-cell isolation microbead cocktail over a QuadroMACS magnetic separator (Miltenyi Biotec, Sunnyvale, CA). The naive phenotype $\left(\mathrm{CD} 25^{-} \mathrm{CD} 44^{\text {lo }} \mathrm{CD} 2 \mathrm{~L}^{\mathrm{hi}} \mathrm{CD} 69^{-}\right)$and purity (approximately $90 \%$ for P14 and P14.GFP; approximately 50\% for H-Y) of each preparation was confirmed by flow cytometry.

\section{Primary T-cell cultures}

Enriched CD8 ${ }^{+} \mathrm{T}$ cells $\left(1.25-2.5 \times 10^{4} /\right.$ well $)$ were incubated at $37^{\circ} \mathrm{C}$ in RPMI 1640 medium supplemented with $10 \%$ FBS, $5 \times 10^{-5}$ M 2-mercaptoethanol, $2 \mathrm{mM}$ L-glutamine, $10 \mathrm{mM}$ HEPES ( $N$-2-hydroxyethylpiperazine$N^{\prime}$-2-ethanesulfonic acid) buffer, $100 \mu \mathrm{g} / \mathrm{mL}$ streptomycin, and $100 \mathrm{IU} / \mathrm{mL}$ penicillin (R-10) in duplicate or triplicate $200-\mu \mathrm{L}$ cultures in $96-$ well flat-bottomed plates. In cytotoxicity experiments, R-10 medium contained 20 ng/mL murine interleukin (IL)-7 (Peprotech, Rocky Hill, NJ). Tetramers were added to a final concentration of $5 \mathrm{nM}$ unless otherwise indicated, and were removed after 2 hours by repeated washing with R-10 prior to additional incubation.

\section{Adoptive transfer and tetramer injections}

Enriched CD8 ${ }^{+} \mathrm{T}$ cells $\left(2 \times 10^{5}-1 \times 10^{7} /\right.$ mouse $)$ were washed and resuspended in PBS, and injected intravenously $(200 \mu \mathrm{L})$ via the lateral tail vein.
Similarly, tetramers (22.2-44.4 pM) were diluted in PBS and injected intravenously $(200 \mu \mathrm{L})$ or into the footpad $(25 \mu \mathrm{L})$.

\section{Cell staining and flow cytometry}

Single-cell suspensions from both in vitro and in vivo experiments were washed in fluorescence-activated cell sorter (FACS) buffer (2\% FBS and $0.1 \% \mathrm{NaN}_{3}$ in PBS) and stained with fluorochrome-conjugated or biotinylated antibodies (Abs), or PE-conjugated tetramers, for 15 to 30 minutes at $4^{\circ} \mathrm{C}$ in a 96-well round-bottomed plate. Secondary staining with SA-Alexa Fluor 488 or SA-allophycocyanin (APC) was performed identically, and cells were fixed with $1 \%$ buffered formaldehyde. For internalization experiments, $\mathrm{T}$ cells were incubated for 5 minutes in either FACS buffer or in $0.5 \mathrm{M} \mathrm{NaCl} / 0.5 \mathrm{M}$ acetic acid $(\mathrm{pH} 2.5)$ prior to analysis. For determination of mitochondrial membrane potential $\left(\Delta \psi_{\mathrm{m}}\right)$, unfixed T cells were analyzed immediately after staining with surface activation markers and $\operatorname{DiIC}_{1}{ }^{5}\left(1,1^{\prime} 3,3,3,3^{\prime} 3^{\prime}\right.$-hexamethylindodicarbocyanine iodide; Molecular Probes, Eugene, OR) in R-10 for 15 minutes at $37^{\circ} \mathrm{C}$, followed by a similar 15-minute incubation with 7-aminoactinomycin D (7-AAD). In all analyses, negative controls were established by either using an isotype $\mathrm{Ab}$ or noncognate tetramer, or by omitting the primary Ab. Live cells were discriminated by scatter properties and staining with 7-AAD. List mode data were collected with a FACSCalibur flow cytometer (BD Biosciences, San Diego, CA), and analyzed with Summit software (versions 3.1 and 4; DakoCytomation, Carpinteria, CA). The following fluorochrome-conjugated or biotinylated monoclonal Abs (mAbs) (from BD Biosciences or eBioscience, San Diego, CA) were used in these experiments (clones are indicated in parentheses): anti-TCR C $\beta$ (H-57), anti-TCR V $\alpha 2$ (B20.1), anti-TCR H-Y (T3.70), anti-CD4 (GK1.5); anti-CD8 $\alpha$ (53-6.7), antiCD11c (N418), anti-CD14 (rmC5-3), anti-CD19 (1D3), anti-CD25 (PC61), anti-CD44 (IM7), anti-CD62L (MEL-14), anti-CD69 (H1.2F3), anti-NK1.1 (PK136), and antitrinitrophenol (anti-TNP; G235-2356). A fluoroscein isothiocyanate (FITC)-labeled chicken polyclonal anti-SAP Ab was purchased from Advanced Targeting Systems, and a PE-labeled rabbit polyclonal anti-FITC Ab was obtained from Molecular Probes.

\section{Tetramer toxicity}

After baseline body weights and blood samples were obtained, C57BL/6J mice were randomly assigned to 1 of 3 treatment groups, receiving either nontoxic tetramer $(22.2 \mathrm{pM})$ or SAP-coupled tetramer at low $(22.2 \mathrm{pM})$ or high $(66.6 \mathrm{pM})$ dose. Venous blood was collected from the superficial temporal vein ("submandibular" bleeding) using a 5-mm Goldenrod lancet (MEDIpoint Inc, Mineola, NY) 2, 7, and 12 days after injection. Serum was separated from the clot by centrifugation (12 $500 \mathrm{rpm}$ for 20 minutes) and stored frozen at $-20^{\circ} \mathrm{C}$. Samples $(25 \mu \mathrm{L}$ per mouse) from each time point were pooled by treatment group and assayed for creatinine, total bilirubin, and alanine aminotransferase (ALT) activity with a Roche/Hitachi 912 chemistry analyzer (Basel, Switzerland). Mice were weighed 3 times weekly through day 24 and at death on day 30 . At that time, the left liver lobe and left kidney were removed, halved, fixed with $10 \%$ buffered formalin, and embedded in paraffin. Mounted sections ( $4 \mu \mathrm{m}$ in thickness) were stained with hematoxylin and eosin and evaluated in blinded fashion by a board-certified veterinary pathologist (J.M.C.).

\section{Confocal microscopy}

Following 30 minutes of loading with unlabeled or PE-labeled tetramers at $4^{\circ} \mathrm{C}$, and 1 hour of incubation at $37^{\circ} \mathrm{C}$, acid-stripped and washed $\mathrm{P} 14 \mathrm{~T}$ cells were permeabilized using a Cytofix/Cytoperm kit (BD Biosciences) and successively stained with a rat anti-CD107a mAb (1D4B), a biotinylated antirat mAb (RG7/1.30), and SA-Alexa Fluor 647. T cells were subsequently incubated for 10 minutes with DAPI (4,6 diamidino-2-phenylindole; Molecular Probes) in PBS/10 mM glycine, resuspended in FluorSave reagent (Calbiochem, San Diego, CA), mounted on glass slides, and coverslipped. Images were acquired at $22^{\circ} \mathrm{C}$ on a Zeiss Axioplan 2 microscope (Everest Digital Microscopy Workstation; Intelligent Imaging Innovations, Denver, CO) with DIC, DAPI, Cy3, and Cy5 filters, using a $63 \times / 1.4$ numerical aperture oil objective and a Photometrics CoolSNAP HQ 
camera (Photometrics, Tucson, AZ). Image stacks were deconvolved using Slidebook 3.0.10 software (Intelligent Imaging Innovations), and stored in TIFF format.

\section{Statistical analyses}

Data were analyzed using Prism 4.0 (GraphPad Software, San Diego, CA). Dose-response curves for cytotoxic tetramers were established by sigmoid curve-fitting, and $\mathrm{EC}_{50}$ values were determined by nonlinear regression analysis. Differences in means between treatments were calculated, as appropriate, by either 2-tailed $t$ test, or analysis of variance (ANOVA) procedure with the Dunnett multiple comparisons post test. In all analyses, the level of significance was set at a $P$ value less than .05 , and graphical results are displayed as the arithmetic mean \pm standard error.

\section{Results}

\section{$\mathrm{CD8}^{+} \mathrm{T}$ cells internalize surface-bound MHC class I tetramer}

To select an appropriate (ie, surface- or internally active) toxin for construction of a cytotoxic tetramer, it was necessary to determine the fate of bound tetramer. To accomplish this, we used P14 T cells, which bear a transgenic $\alpha \beta$ TCR that recognizes the lymphocytic choriomeningitis virus peptide $\mathrm{gp}_{33-41}$ (gp33) presented by the $\mathrm{H} 2-\mathrm{D}^{\mathrm{b}}$ molecule. ${ }^{25}$ These $\mathrm{CD} 8^{+} \mathrm{T}$ cells can be targeted in vivo by cognate tetramer. The gp33 APL C9M was used to prepare the high-avidity tetramer gp $33[\mathrm{C} 9 \mathrm{M}]-\mathrm{D}^{\mathrm{b}}$ (henceforth designated by the shorthand gpC9M). Following footpad injection, PE-labeled gpC9M can be found on P14.GFP T cells in the popliteal lymph node, leading to increased expression of the surface activation marker CD25 (Figure 1A). By 24 hours after injection, gpC9M-PE is no longer detectable (not shown), presumably due to either dissociation from the cell surface, or endocytosis and degradation. Consistent with the latter hypothesis, Whelan et al observed internalized class I tetramers by confocal microscopy. ${ }^{26}$ Similarly, we found colocalization of gpC9M-PE with the lysosome-associated membrane protein LAMP-1 after 60 minutes of incubation at $37^{\circ} \mathrm{C}$ (Figure 1B). No fluorescence was observed after incubation with a control high-avidity tetramer specific for $\mathrm{H}-\mathrm{Y}$ (male-specific minor histocompatibility antigen)-reactive $\mathrm{CD}^{+} \mathrm{T}$ cells ${ }^{27}\left(\mathrm{H}-\mathrm{Y}[\mathrm{C} 2 \mathrm{~A}]-\mathrm{D}^{\mathrm{b}}{ }_{-}\right.$ $\mathrm{PE}$, designated hyC2A-PE; not shown). We next determined the time course and extent of tetramer internalization. The TCR complex undergoes endocytosis as an intact unit after ligand binding. ${ }^{28}$ We reasoned that bound tetramers were internalized during this process. To examine this possibility, we loaded the surface of P14 $\mathrm{T}$ cells with gpC9M-PE and a FITC-labeled, anti-TCR constant region $(\mathrm{C} \beta) \mathrm{mAb}$ at $4^{\circ} \mathrm{C}$. $\mathrm{T}$ cells were then incubated additionally at either $37^{\circ} \mathrm{C}$ or $4^{\circ} \mathrm{C}$ to permit or inhibit internalization, respectively. Exposure to cold is effective in preventing TCR endocytosis, while pharmacologic agents, such as cytochalasin D, cycloheximide, or azide, are not. ${ }^{29}$ External fluorescence was removed by stripping cell-surface proteins with an acetic acid solution. As seen in Figure 1C (left panel), metabolically active $\left(37^{\circ} \mathrm{C}\right) \mathrm{T}$ cells rapidly accumulate acidresistant $\mathrm{PE}$ fluorescence, indicating that the tetramer was internalized. The kinetics of this process are identical to TCR (FITC) internalization (Figure 1C; right panel), suggesting coentrance into the $\mathrm{T}$ cell. These experiments also show that by 30 minutes, virtually all P14 $\mathrm{T}$ cells have endocytosed gpC9M-PE, implying that $100 \%$ of the target population will be susceptible to an internally active toxin (Figure 1D).

\section{A SAP-coupled tetramer is internalized after TCR-specific binding}

Based on these results, we prepared a candidate cytotoxic tetramer by coupling biotinylated pMHC monomers to a SA-SAP conjugate molecule. Ribosome-inactivating toxins such as SAP cause cell death by cleaving an adenosine in $28 \mathrm{~S}$ rRNA, irreversibly inhibiting protein synthesis. In their native form, type I RIPs are relatively nontoxic because of their inability to bind and enter mammalian cells. Coupling of SA-SAP to pMHC molecules did not diminish its toxicity, as demonstrated by the similar degree of ribosome inhibition by gpC9M-SAP and the parent SA-SAP in a cell-free translation assay (Figure 2A). To verify that tetramers prepared with SA-SAP could still bind cognate $\mathrm{CD} 8^{+} \mathrm{T}$ cells, $\mathrm{P} 14 \mathrm{~T}$ cells were incubated with gpC9M-SAP, hyC2A-SAP, or gpC9M plus a molar equivalent of free (unconjugated) SAP. Subsequent staining with anti-SAP Abs shows that antigen-restricted binding was preserved (Figure 2B). It was also possible that a SAP-coupled tetramer could bind to other cell types via interactions with the SAP or SA molecules. ${ }^{30}$ Using the same Ab-staining technique, however, we did not find binding of the SAP-coupled tetramer to other immune cells (Figure 2C), suggesting that bystander toxicity would be minimal.

A

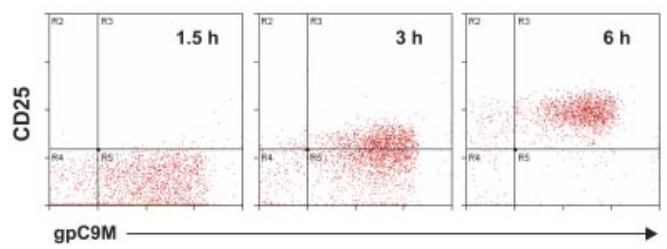

C

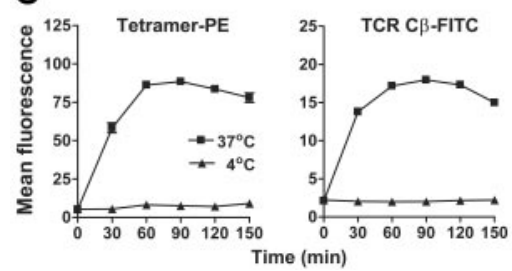

B

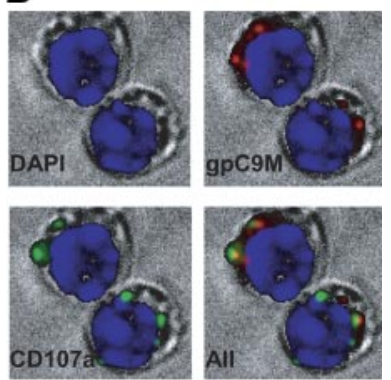

D

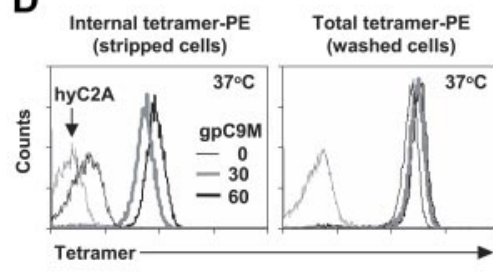

Figure 1. $A D^{b}-P E$ tetramer binds and is internalized by cognate $\mathbf{T}$ cells. (A) Bound tetramer is visible on adoptively transferred P14.GFP T cells in the lymph node after injection of gpC9M-PE, causing activation. Histograms are gated on $\mathrm{GFP}^{+}$ $\mathrm{CD}^{+} \mathrm{T}$ cells; there was no increase in CD25 expression on host $\mathrm{GFP}^{-} \mathrm{CD}^{+} \mathrm{T}$ cells. (B) Internalized tetramer colocalizes with LAMP-1 (CD107a), as visualized by confocal microscopy of acid-stripped P14 T cells. Both surface and internal gpC9M-PE tetramers were observed with nonstripped cells (not shown). In all panels, original magnification was $\times 630$. (C) Bound gpC9M-PE tetramer and the TCR are internalized rapidly at $37^{\circ} \mathrm{C}$, with identical kinetics. For clarity, only data from acid-stripped cells (ie, internal fluorescence) is shown. (D) All metabolically active T cells have internalized tetramer by 30 minutes. P14 T cells incubated with gpC9M-PE show a progressive increase in acid-resistant fluorescence over time (time points $>60$ minutes not shown). Results represent 2 independent experiments. In all experiments, control tetramers flu-PE (A) and hyC2A-PE (B-D) and the control FITC-labeled hamster anti-TNP mAb (C-D), did not bind, activate, or enter P14.GFP or P14 T cells (not shown). 

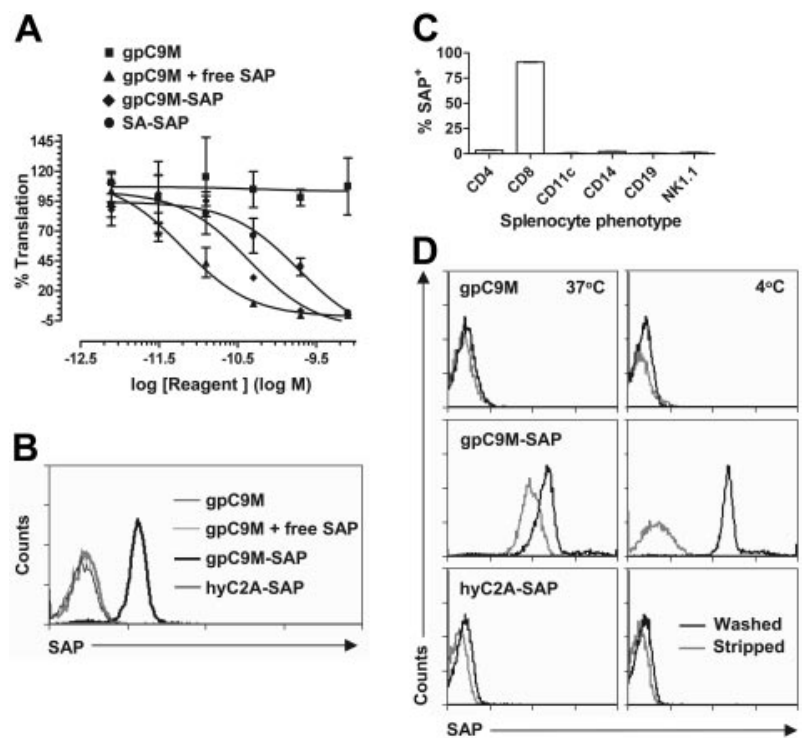

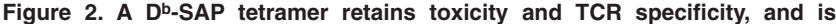
endocytosed by target $T$ cells in vitro. (A) Coupling of SA-SAP to pMHC monomers does not diminish SAP potency. The gpC9M-SAP tetramer and SA-SAP demonstrate similar ribosome inhibition in a rabbit reticulocyte lysate translation assay. Nonlinear regression was used to calculate $\mathrm{EC}_{50}$ values (free SAP, $6.4 \mathrm{pM}$; SA-SAP, $190 \mathrm{pM}$; and gpC9M-SAP, $43.8 \mathrm{pM}$ ). (B) Coupling of SAP to pMHC monomers does not alter tetramer-binding specificity, and free SAP does not bind CD8 ${ }^{+} \mathrm{T}$ cells. FITC-labeled anti-SAP Abs were only detected on P14 T cells following incubation with the cognate gpC9M-SAP tetramer. (C) A SAP-coupled tetramer does not bind to $\mathrm{B}$ cells, $\mathrm{CD} 4^{+}$cells, or NK T cells, or to antigen-presenting cells. The CD8 ${ }^{+}$ T-cell population alone was labeled with anti-SAP Abs after incubation of bulk P14 splenocytes with gpC9M-SAP tetramer. $\mathrm{CD}^{+} \mathrm{T}$ cells constituted approximately $7 \%$ of splenocytes in these transgenic mice. (D) A SAP-coupled tetramer is internalized by metabolically active cognate $\mathrm{T}$ cells. $\mathrm{P} 14 \mathrm{~T}$ cells incubated at $37^{\circ} \mathrm{C}$ with gpC9M-SAP, but not hyC2A-SAP, exhibit internal PE fluorescence that corresponds to endocytosed SAP. In all experiments, the gpC9M tetramer served as a negative control. Results represent 2 (A, C) or 3 (B, D) separate experiments.

To establish that the SAP-coupled tetramer was internalized efficiently, we again compared the fate of bound tetramer on quiescent $\left(4^{\circ} \mathrm{C}\right)$ and metabolically active $\left(37^{\circ} \mathrm{C}\right) \mathrm{T}$ cells. Cold $\mathrm{P} 14$ $\mathrm{T}$ cells were initially incubated with gpC9M, gpC9M-SAP, or hyC2A-SAP, followed by FITC-labeled anti-SAP Abs, and then, to amplify the signal, by PE-labeled anti-FITC Abs. After additional incubation at the indicated temperatures, we found acid-resistant PE fluorescence, corresponding to the SAP moiety, in all active $\mathrm{T}$ cells exposed to the cognate SAP-coupled tetramer (Figure 2D).

\section{A SAP-coupled tetramer selectively deletes antigen-specific $T$ cells in vitro}

We then evaluated the ability of the $\mathrm{D}^{\mathrm{b}}$-SAP tetramer to kill target $\mathrm{T}$ cells. To accomplish this, it was necessary to compare relative T-cell survival above the background level of activation-induced cell death (AICD) that results from strong TCR stimulation. Because SAP-mediated toxicity depends on internalization, we hypothesized that P14 T-cell cultures exposed to the control tetramer hyC2A-SAP, or to free SAP mixed with the cognate tetramer gpC9M, would not exhibit greater cell loss than those treated with gpC9M alone. The cytotoxicity of hyC2A-SAP was verified by including $\mathrm{H}-\mathrm{Y} \mathrm{T}$ cells in the assay. To determine if killing was selective, the 2 target populations were cultured together and treated with mixtures of gpC9M and hyC2A tetramers to ensure that all $\mathrm{T}$ cells were exposed to identical concentrations of their cognate tetramers. To measure survival, we quantified live cells by exclusion of the impermeant nucleic acid dye 7-AAD. Flow cytometry dotplots (Figure 3A) show the deletion of $\mathrm{V} \alpha 2^{+}$ $\mathrm{P} 14(>60 \%)$ and $\mathrm{T} 3.70^{+} \mathrm{H}-\mathrm{Y}(>75 \%) \mathrm{CD}^{+} \mathrm{T}$ cells by the corresponding antigen-specific SAP-coupled tetramers at 48 hours. Importantly, this effect was cell selective and, at the concentration tested, free SAP was not toxic.

Primary T cells cultured in vitro also can die from neglect, and it is possible that SAP-coupled tetramers caused the death of cognate $\mathrm{T}$ cells simply by providing inadequate stimulation through the TCR. To exclude this possibility, we first compared surface activation markers on $\mathrm{T}$ cells after incubation with nontoxic and cytotoxic tetramers. P14 T cells exposed to gpC9M or gpC9M-SAP showed equivalent changes in the expression of CD62L and CD69 (Figure 3B), and CD25 and CD44 (not shown). When incubated with the control tetramer hyC2A (not shown), P14 T cells displayed the same naive phenotype as freshly isolated cells, or those cultured in medium alone. H-Y T cells incubated with hyC2A and hyC2ASAP also showed identical changes in activation markers (not shown). Upon stimulation with antigen, naive $\mathrm{CD}^{+} \mathrm{T}$ cells exhibit an increase in $\Delta \psi_{\mathrm{m}},{ }^{31}$ which can be measured using the potentialsensitive cationic dye $\mathrm{DiIC}_{1}{ }^{5}$. P14 T cells cultured with gpC9M or gpC9M-SAP demonstrated equivalent increases in the mean fluorescence intensity of $\operatorname{DiIC}_{1}{ }^{5}$ (Figure 3C). Together, these data indicate that SAP-coupled tetramers provide the same magnitude of TCR stimulation as the corresponding nontoxic ligand.

These experiments also show that not all targeted $\mathrm{T}$ cells were eliminated by the cytotoxic tetramer (Figure 3A). This incomplete
Figure 3. $D^{\mathrm{b}}-\mathrm{SAP}$ tetramers activate and eliminate antigenspecific $T$ cells in vitro. (A) Incubation of a 50:50 mixture of female $\mathrm{V}_{\alpha 2} 2^{+}(\mathrm{P} 14)$ and $\mathrm{T}^{3} .70^{+}(\mathrm{H}-\mathrm{Y}) \mathrm{CD}^{+} \mathrm{T}$ cells with gpC9M-SAP or hyC2A-SAP results in the selective loss of cognate $T$ cells. Tetramer mixtures are indicated by the legends above the dotplots. Following an initial 2-hour incubation with tetramer, cells were washed repeatedly and then cultured for an additional 46 hours prior to harvest and staining. For each group, $10^{4}$ events were analyzed; the plots show only live $\left(7-\mathrm{AAD}^{-}\right) \mathrm{CD} 8 \alpha$-gated cells. Numbers indicate the cell number in the region. (B) Loss of $\mathrm{T}$ cells with $\mathrm{D}^{\mathrm{b}}$-SAP tetramer treatment is not the result of inadequate stimulation through the TCR. Exposure to gpC9M or gpC9M-SAP causes equivalent changes in CD62L and CD69 expression, and identical increases in $\Delta \Psi_{\mathrm{m}}$ (measured as increased DilC $_{1}{ }^{5}$ fluorescence), characteristic of antigenactivated T cells. P14 T cells were analyzed after 12 hours of culture; equivalent activation was also found at 8-and 16-hour time points (not shown). Histograms are gated on $7-\mathrm{AAD}^{-}$cells, which are present in equal percentages in tetramer-treated groups. Identical results were obtained in 4 (A) or 2 (B) independent experiments.
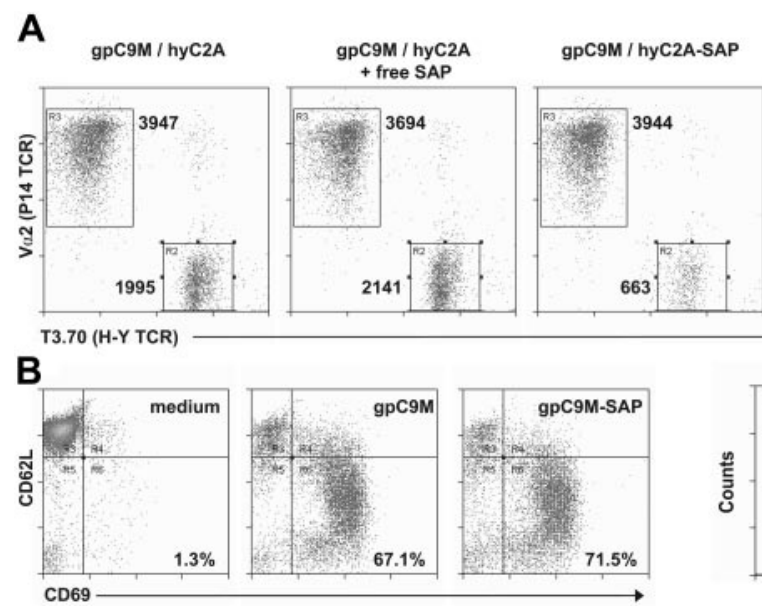

gpC9M-SAP / hyC2A

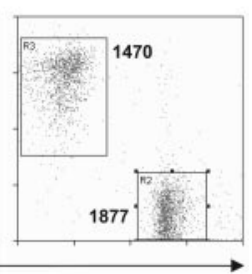

B

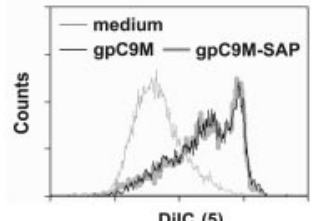


effect could have reflected an insufficient dose, a toxin-resistant subpopulation, or evaluation at a premature time point. Because internalization studies suggested that, at the tetramer dose used, all $\mathrm{T}$ cells appeared to have endocytosed a similar, presumably lethal quantity of SAP (Figure 2D), we first investigated the kinetics of cell killing in separate, side-by-side P14 and H-Y cultures. The time course of H-Y T-cell death is shown in representative dotplots (Figure 4A). By 72 hours, more than $98 \%$ of input H-Y or P14 $\mathrm{T}$ cells were killed by the cognate cytotoxic tetramer (Figure $4 \mathrm{~B}$ ). Similar results were also found in experiments using $\mathrm{H} 2-\mathrm{K}^{\mathrm{d}}-$ restricted, TCR-transgenic $\mathrm{CD}^{+}{ }^{+} \mathrm{T}$ cells and $\mathrm{K}^{\mathrm{d}}-\mathrm{SAP}$ tetramers (not shown).

Internalization of the SAP-coupled tetramer occurs within 1 to 2 hours (Figure 1C). To determine how rapidly initial tetramer binding occurs, we exposed P14 T cells to gpC9M-SAP and washed the cell pellets immediately, or $7.5,15,30,60$, or 120 minutes later. There was no difference in cell killing among any of the treatment groups at 48 hours (not shown), indicating that a lethal number of cytotoxic complexes binds almost instantly to TCRs, and are subsequently endocytosed.

\section{The efficiency of T-cell deletion depends on tetramer avidity and dose}

Because TCR binding is necessary for killing, we reasoned that the cytotoxicity of a SAP-coupled tetramer would depend partly on the avidity of the $\mathrm{T}$ cell-tetramer interaction. To investigate this, we prepared additional P14-specific tetramers from pMHC monomers folded with the native gp33 peptide and the weak agonist APL K1S (gpK1S), and from a mutated $\mathrm{H} 2-\mathrm{D}^{\mathrm{b}}$ molecule (containing an $\alpha 3$ domain D227K substitution) that does not bind the CD8 coreceptor, folded with C9M peptide (gpC9M-D227K). ${ }^{24}$ The avidity of these tetramers had been previously determined by Scatchard analysis using P14 splenocytes $\left(K_{\mathrm{d}}\right.$ : gpC9M, $5.81 \pm 1.36 \mathrm{nM}$; gp33, $19.36 \pm 5.84 \mathrm{nM}$; gpC9M-D227K, $97.59 \pm 46.16 \mathrm{nM}$; and gpK1S, not measurable). ${ }^{24}$ Relative cytotoxicities of the different SAPcoupled tetramers were compared over a dose range from 0.008 to $5 \mathrm{nM}$. Because the dose-related cytotoxic effects of tetramers in vitro can be confounded by high levels of AICD at nanomolar or greater concentrations, and death by neglect at picomolar or lesser concentrations, we serially diluted PE- and SAP-coupled tetramers with their unlabeled counterparts so that all $\mathrm{T}$ cells were exposed to the same total concentration $(5 \mathrm{nM})$. The comparative binding of the tetramers can be visualized by flow cytometry (Figure 5A). The hyC2A-PE (not shown) and gpK1S-PE tetramers and their corresponding SAP-coupled constructs neither bound nor killed P14 T cells. All 3 SAP-coupled tetramers with measurable avidities exhibited dose-dependent cytotoxicity (Figure 5B; Table 1). Small differences in avidity (gpC9M vs gp33) did not result in significantly different $\mathrm{EC}_{50}$ values; however, the much weaker avidity (larger $K_{\mathrm{d}}$ ) of the gpC9M-D227K tetramer was associated with a significant decline in T-cell killing. These experiments also show that the CD8-MHC interaction is dispensable for tetramer binding, internalization, and cytotoxicity.

\section{A SAP-coupled tetramer deletes Ag-specific T cells in vivo}

Last, we evaluated the ability of the $\mathrm{D}^{\mathrm{b}}-\mathrm{SAP}$ tetramer to delete cognate $\mathrm{CD}^{+}{ }^{+} \mathrm{T}$ cells in vivo. An equal mixture of female P14.GFP and $\mathrm{H}-\mathrm{Y} \mathrm{T}$ cells were adoptively transferred into C57BL/6J mice, and after allowing 24 hours for redistribution, recipients were injected with gpC9M or gpC9M-SAP. The tetramer dose (22.2 pM) provided an approximate SAP dose of $0.085 \mathrm{mg} / \mathrm{kg}$, which is well below the $\mathrm{LD}_{50}$ of 0.4 to $1.0 \mathrm{mg} / \mathrm{kg}$ reported for mAb-SAP immunotoxins. ${ }^{32,33}$ A single injection of gpC9M-SAP tetramer selectively deleted more than $75 \%$ of target T cells within 72 hours (Figure 6A-B). The percentage and number of control H-Y T cells did not differ between groups, indicating that the loss of P14.GFP T cells with gpC9M administration could not be attributed to inefficient adoptive transfer or poor cell recovery. No overt signs of toxicity were observed with treatment. To assess potential acute or chronic adverse effects of the immunotoxin, a $\mathrm{D}^{\mathrm{b}}$-SAP tetramer was given at either the dose effective at deleting T cells (22.2 pM), or at a 3 -fold-increased dose $(66.6 \mathrm{pM})$. Following injection, mice were monitored for change in body weight, which is a sensitive indicator of rodent health, and for biochemical and histologic evidence of injury to the liver or kidney, which are reported to be the target organs of SAP. ${ }^{34}$ Even with administration of the higher dose, no behavioral signs of illness were noted, although a decrease in body weight was seen (Figure 7A). The onset and resolution of
A

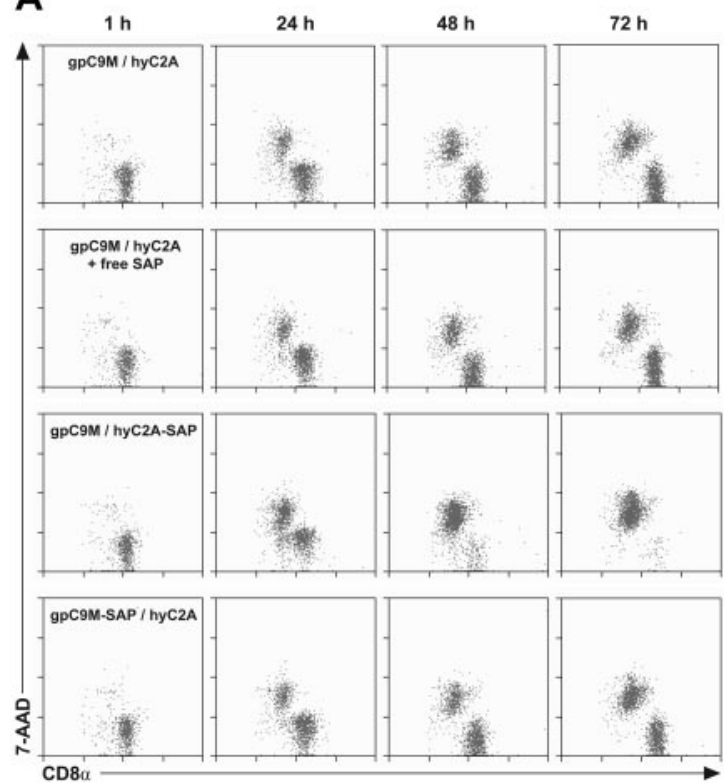

B

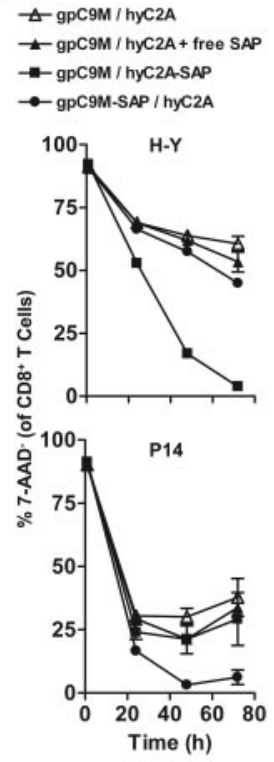

Figure 4. $\mathrm{D}^{\mathrm{b}}$-SAP tetramers eliminate most cognate $\mathrm{CD} 8^{+} \mathrm{T}$ cells in vitro within 72 hours. (A) Representative dotplots show the time course of deletion of female $\mathrm{H}-\mathrm{Y}$ T cells incubated with hyC2A-SAP. (B). Kinetics of $D^{b}$-SAP tetramer-mediated deletion of $\mathrm{H}-\mathrm{Y}$ (top) and P14 (bottom) T cells. Identical results were obtained in 3 independent experiments. 

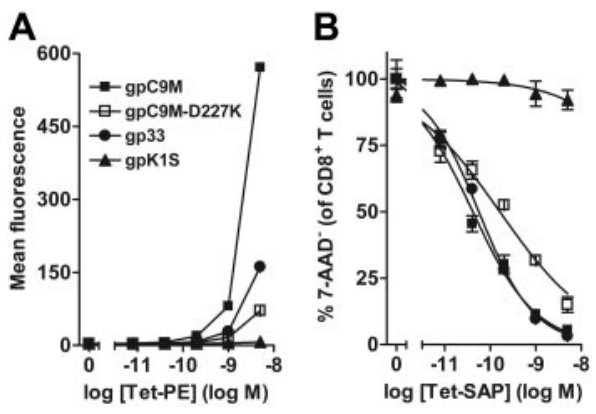

Figure 5. Killing of $\mathrm{CDB}^{+} \mathrm{T}$ cells by a $\mathrm{D}^{\mathrm{b}}-\mathrm{SAP}$ tetramer depends on tetramer dose and avidity. (A) Mean fluorescence intensity of P14 T cells stained with $\mathrm{PE}$-labeled cognate tetramers of varying avidity. The gpC9M tetramer binds with the highest efficiency. (B) $\mathrm{D}^{\mathrm{b}}$-SAP tetramers kill target $\mathrm{T}$ cells in a dose-dependent fashion. Cytotoxicity was normalized to cultures treated with unlabeled tetramer alone. The $\mathrm{EC}_{50}$ of the SAP-coupled gpC9M-D227K, which cannot bind the CD8 coreceptor and hence binds P14 T cells with much lower avidity than gpC9M or gp33, was significantly different $\left({ }^{*} P<.001\right.$; Table 1$)$. Incubation with control PEor SAP-coupled hyC2A (not shown) gave identical results to that obtained with gpK1S; $\mathrm{EC}_{50}$ values could not be determined for these tetramers. Results represent 3 independent experiments.

weight loss was temporally correlated with a transient hepatopathy marked by elevated serum concentrations of the liver-specific cytosolic enzyme ALT (Figure 7B, top panel). With the low dose of SAP-coupled tetramer, the increase in ALT was mild and shortlived. No changes in serum total bilirubin (Figure 7B, bottom panel) accompanied treatment, and the livers of all mice appeared histologically normal when evaluated 30 days after injection. Several mice that received the high dose of cytotoxic tetramer had isolated small renal tubules containing acellular casts. This change was not observed with low-dose administration, and in all groups, serum creatinine remained normal $(<17.68 \mu \mathrm{M}[0.2 \mathrm{mg} / \mathrm{dL}])$ at all time points.

\section{Discussion}

We used an MHC class I tetramer for selective delivery of a cytotoxic molecule to T cells. H2-D ${ }^{\mathrm{b}}$ tetramers linked to a Type 1 RIP bound, activated, and were internalized by cognate $\mathrm{T}$ cells to the same degree as traditional, fluorophore-labeled tetramers. SAP-coupled tetramers specific for P14 and H-Y TCRs selectively deleted target $\mathrm{T}$ cells in mixed-cell cultures. In vivo administration of the $\mathrm{D}^{\mathrm{b}}$-SAP tetramer reduced antigen-specific $\mathrm{T}$ cells in the spleen by more than $75 \%$.

A tetramer-directed toxin could represent a potent new technology for eliminating specific deleterious T-cell responses in autoimmune and transplantation-related diseases. Among the most significant recent advances in the treatment of cancer are Ab-targeted therapies, capable of selectively destroying neoplastic cells. For lymphoid malignancies, these agents include the anti-CD20 mAbs rituximab, ibritumomab $\left({ }^{90} \mathrm{Y}\right.$-congugated $)$, and tositumomab $\left({ }^{131} \mathrm{I}\right.$ congugated); ${ }^{36,37}$ the anti-CD22 mAb epratuzumab; ${ }^{38}$ and the

Table 1. Relative cytotoxicities of $D^{\mathrm{b}}$-SAP tetramers with varying aridities for target P14 T cells

\begin{tabular}{lc}
\hline \multicolumn{1}{c}{ Tetramer } & EC $_{50}, \mathrm{pM}$ \\
\hline gpC9M & $41.3(31.7-53.7)$ \\
gpC9M-D227K & $162.0(107.9-243.2)^{*}$ \\
gp33 & $55.9(44.0-71.1)$ \\
\hline
\end{tabular}

The $95 \%$ confidence intervals are shown in parentheses

${ }^{\star} P<.001$.
A
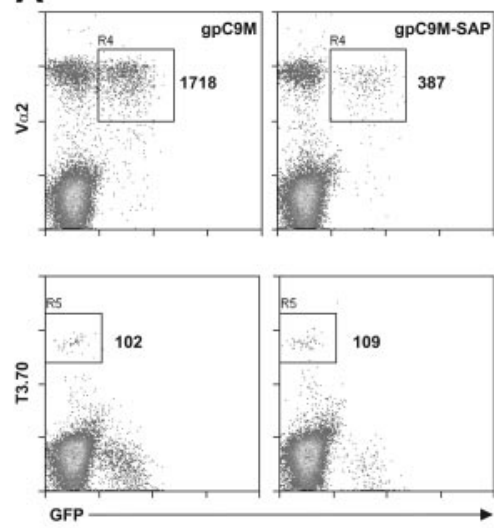

B
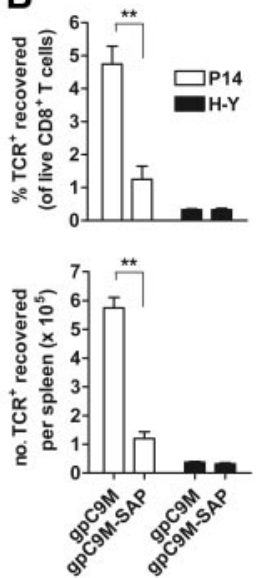

Figure 6. A $D^{\mathrm{b}}-\mathrm{SAP}$ tetramer can delete antigen-specific $\mathrm{CD}^{+} \mathrm{T}$ cells in vivo. (A) Administration of a gpC9M-SAP tetramer selectively eliminates adoptivelytransferred P14.GFP $\left(\mathrm{GFP}^{+} \mathrm{V} \alpha 2^{+}\right)$but not $\mathrm{H}-\mathrm{Y}\left(\mathrm{T} 3.70^{+}\right) \mathrm{T}$ cells from the spleen of C57BL/6J recipient mice ( $n=3 /$ group) at 72 hours. Representative histograms (top and bottom panels are from the same mouse) show a CD8 ${ }^{+} \mathrm{T}$-cell-gated population. An identical number of total events $\left(3.0 \times 10^{5}\right)$ were collected in each sample, and cell viability, measured by 7-AAD exclusion, was equivalent between groups. Numbers indicate cell counts in the region. (B) The loss of P14.GFP T cells with gpC9M-SAP versus gpC9M was significant ${ }^{* \star} P<.005$ by 2 -tailed Student $t$ test); differences between H-Y T cells were not significant. Results represent 2 independent experiments.

anti-CD52 mAb alemtuzumab. ${ }^{39}$ Unfortunately, to date, the use of Ab-based deletional therapies to induce T-cell tolerance has not produced equivalent clinical successes. Neither alemtuzumab nor antithymocyte globulin treatment, for example, have improved long-term outcomes in multiple sclerosis or diabetes mellitus. ${ }^{40,41}$ While effective in preventing graft rejection, administration of these relatively nonselective agents also carries risks of delayed immune recovery and serious opportunistic infections. ${ }^{42,43}$ Development of an agent capable of targeting specific $\mathrm{T}$ cells therefore remains a critical therapeutic objective.

\section{A}

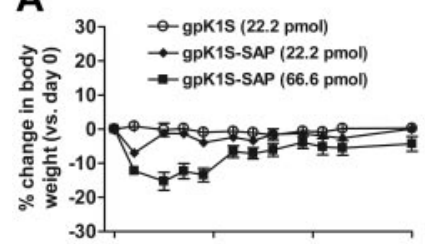

B
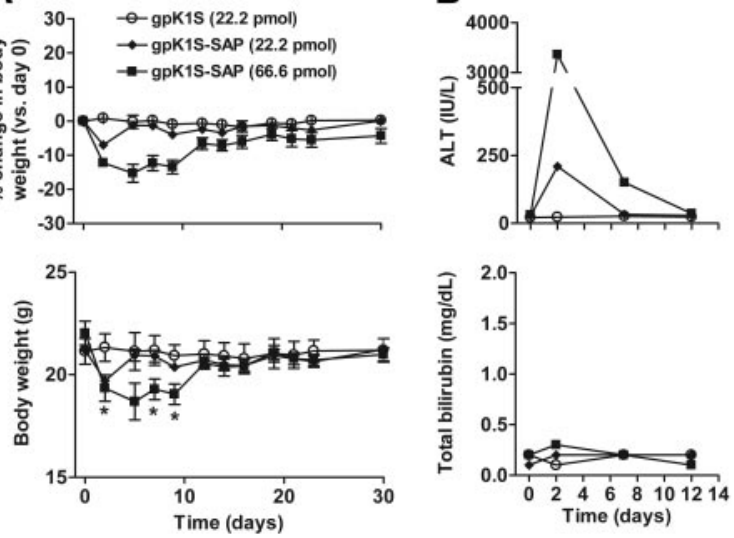

Figure 7. $A D^{\mathrm{b}}$-SAP tetramer is associated with reversible hepatotoxic effects (A) Administration of gpK1S-SAP tetramer to C57BL/6J mice ( $n=5$ per group) results in temporary weight loss. The top panel depicts the mean percentage change over time versus pretreatment body weights; the bottom panel displays mean body weights. Only the weight loss in the high dose group was significant $\left({ }^{*} P<.05\right.$ by ANOVA vs treatment with nontoxic tetramer) at the indicated time points. (B) Administration of gpK1S-SAP causes an increase in serum ALT that resolves by 12 days after administration. Serum bilirubin was unaffected by treatment. In control mice injected with the nontoxic tetramer, serum biochemical values at all points were consistent with published reference ranges (ALT: $44-87 \mathrm{IU} / \mathrm{L}$; creatinine: 42.4-97.2 $\mu \mathrm{M}$ [0.48-1.1 $\mathrm{mg} / \mathrm{dL}]$; and total bilirubin: 5.1-13.7 $\mu \mathrm{M}$ [0.3-0.8 mg/dL]). ${ }^{35}$ 
Experimental studies evaluating the killing of $\mathrm{T}$ cells with immunotoxins have been reported previously. Typically, the specificity of these conjugates is determined by a surface antigen that defines a subpopulation rather than a clonotype. For example, activated $\mathrm{T}$ cells have been targeted with anti-CD25 or anti-CD152 (CTLA-4) mAbs linked to SAP. ${ }^{44,45}$ As pharmacologic agents, such immunotoxins would offer little gain in selectivity over currently available immunosuppressive drugs, and the benefit of eliminating auto- or graft-reactive CTLs could be outweighed by the unintended deletion of regulatory $\mathrm{T}$ cells bearing the same markers. While generation of a mAb-directed immunotoxin against a particular TCR is possible, the technical difficulty in preparing native idiotype protein for immunization precludes ready implementation of this approach. The feasibility of using pMHC targeting to kill specific T cells was demonstrated recently using tetramers conjugated to the cytotoxic alpha-particle emitter actinum-225, although in vivo effects were not evaluated. ${ }^{21}$

In addition to their clonotypic specificity and relative ease of preparation, T-cell immunotoxins constructed from pMHC molecules possess other potential advantages over their mAb-based counterparts. Within a heterogeneous population of specific autoor graft-reactive $\mathrm{CD} 8^{+} \mathrm{T}$ cells, some pathogenic TCRs may be sufficiently distinct antigenically from the representative idiotype to escape recognition by an anti-idiotype mAb immunotoxin. Consequently, such treatment would rapidly select for the immunotoxin-resistant clone. In contrast, by mimicking the natural TCR ligand, a cytotoxic tetramer can effectively target virtually all functionally relevant, deleterious T cells. Because the cytotoxicity of the SAP-coupled tetramer depends on its avidity for the T cell (Figure 5B; Table 1), however, it is likely that a small percentage of low-avidity, antigen-specific T cells will not be killed. Paradoxically, such permissiveness may be beneficial in the treatment of some autoimmune diseases. In one animal model, the occupancy of target organs with low-avidity, clonotypic $\mathrm{CD}^{+} \mathrm{T}$ cells following selective eradication of high-avidity effectors prevented overt disease, while more extensive deletion did not. ${ }^{46}$ The sparing of protective $\mathrm{T}$ cells might be enhanced by altering the avidity of the tetramer, which can be accomplished quite easily by substitution of APLs for the native epitope.

Several obstacles could hinder the successful use of a cytotoxic tetramer. Binding to surface molecules independent of the TCR may lead to endocytosis and lethal effects in nontarget cells. For example, sufficient SAP-coupled tetramer might bind via the CD8 coreceptor alone to kill noncognate T cells. In our study, however, we did not observe nonspecific tetramer binding, consistent with other reports, ${ }^{17,47}$ nor did we find nonselective cytotoxicity in mixed T-cell experiments. If this interaction ultimately proves to be consequential, then tetramers can be prepared using mutated heavy chains that abrogate MHC-CD8 binding, which appears unnecessary for killing (Figure 5B; Table 1). The increase in serum ALT activity that we observed (Figure 7B; top panel) indicates that hepatocytes are nonspecific targets of the SAP-coupled tetramer, similar to findings with mAb-based immunotoxins. ${ }^{34}$ The rapid return of hepatic enzyme activity to the normal range, together with the absence of any histologic changes, suggests that the liver insult mediated by the cytotoxic tetramer, even at 3 times the effective dose, is reversible. Nevertheless, it should also be noted that, while SAP is a convenient toxin to establish the proof of principle of a cytotoxic tetramer, therapeutic use of this type I RIP might not be optimal. It is conceivable, for example, that pMHC-guided delivery of an agent that disables vital T-cell-specific intracellular pathways could be equally as effective while minimizing or preventing systemic toxicity. A second obstacle is the tetramer-mediated activation of target $\mathrm{T}$ cells, which would be harmful if killing is inefficient. Binding of the TCR by tetramers or mAbs can initiate intracellular signaling cascades, leading to priming and expansion. The SAP-coupled tetramers stimulated $\mathrm{T}$ cells equally as well as nontoxic tetramers (Figure 3B), and while essentially all targets were killed in vitro (Figure 4B), P14 T cells were still recoverable 3 days after a single injection of gpC9M-SAP (Figure 6A). Determining the functional phenotype of these surviving $\mathrm{T}$ cells will be an important next step in assessing this potential hazard, which might be overcome by taking advantage of the relatively simple means (in contrast to mAbs) of manipulating tetramerbinding characteristics. Thus, tetramers folded with candidate APLs could be screened in vitro for T-cell binding, stimulation, and cytotoxicity, allowing the selection of antagonist peptides that result in efficient killing with minimal activation. ${ }^{48,49}$ Last, the survival of some target $T$ cells after 1 injection of tetramer suggests that complete eradication may require multiple doses, which we are currently investigating. A possible consequence of repeated administration is the development of Abs against nonself-components of the tetramer, which is a well-recognized obstacle to extended treatment with conventional immunotoxins. The inherent flexibility of the tetramer system may provide an answer for this problem by allowing simple substitution of less-immunogenic components: for example, by using DNA, rather than streptavidin, to form $\mathrm{pMHC}$ multimers and link the toxic moiety.

This study demonstrates that tetrameric pMHC complexes can deliver a lethal dose of toxin to specific T cells in vitro and in vivo, with minimal bystander killing. By deleting pathogenic T-cell populations to induce specific tolerance, such cytotoxic tetramers should prove very useful as primary therapy for selected immunemediated diseases.

\section{Acknowledgments}

We thank Denise Higgins at Advanced Targeting Systems for assistance with the ribosome inhibition assay.

Supported by a National Institutes of Health (NIH) grant R01 GM 067143 (J.A.F.) and a Juvenile Diabetes Research Foundation grant (P.R.H.).

\section{Authorship}

Author contributions: P.R.H. designed research, performed experiments, and wrote the paper; C.B., M.D.W., and M.D.L.J. performed research (monomer preparation, confocal microscopy, and animal care and phenotyping); J.M.C. performed histopathologic analyses; E.J.C. and J.A.F. contributed reagents and participated in experiment design and data analysis; and all authors reviewed the final version of the manuscript.

Conflict-of-interest statement: The authors declare no competing financial interests.

Correspondence: Paul R. Hess, Department of Clinical Sciences, College of Veterinary Medicine, North Carolina State University, Box 8401, 4700 Hillsborough St, Raleigh, NC 27606; e-mail:paul_hess@ncsu.edu. 
From www.bloodjournal.org at North Carolina State University Libraries on January 7, 2009. For personal use

BLOOD, 15 APRIL 2007 • VOLUME 109, NUMBER 8

only.

DELETION OF CD8

\section{References}

1. Kurts C, Miller JF, Subramaniam RM, Carbone FR, Heath WR. Major histocompatibility complex class I-restricted cross-presentation is biased towards high dose antigens and those released during cellular destruction. J Exp Med. 1998;188:409-414.

2. Kelly DA. Long-term challenges of immunosuppression in pediatric patients. Transplant Proc. 2005;37:1657-1662

3. Bacigalupo A, Palandri F. Management of acute graft versus host disease (GvHD). Hematol J. 2004;5:189-196.

4. Horwitz ME, Sullivan KM. Chronic graft-versushost disease. Blood Rev. 2006;20:15-27.

5. Miller LW. Cardiovascular toxicities of immunosuppressive agents. Am J Transplant. 2002;2: 807-818.

6. Drachenberg CB, Klassen DK, Weir MR, et al. Islet cell damage associated with tacrolimus and cyclosporine: morphological features in pancreas allograft biopsies and clinical correlation. Transplantation. 1999;68:396-402.

7. Penn I. Post-transplant malignancy: the role of immunosuppression. Drug Saf. 2000;23:101-113.

8. Fishman JA, Rubin RH. Infection in organ-transplant recipients. N Engl J Med. 1998;338:17411751.

9. Herold KC. Treatment of type 1 diabetes mellitus to preserve insulin secretion. Endocrinol Metab Clin North Am. 2004;33:93-111.

10. Goodin DS, Frohman EM, Garmany GP Jr, et al. Disease modifying therapies in multiple sclerosis: report of the Therapeutics and Technology Assessment Subcommittee of the American Academy of Neurology and the MS Council for Clinical Practice Guidelines. Neurology. 2002;58:169178.

11. Katz J, Benoist C, Mathis D. Major histocompatibility complex class I molecules are required for the development of insulitis in non-obese diabetic mice. Eur J Immunol. 1993;23:3358-3360.

12. Serreze DV, Leiter EH, Christianson GJ, Greiner D, Roopenian DC. Major histocompatibility complex class I-deficient NOD-B2mnull mice are diabetes and insulitis resistant. Diabetes. 1994;43: 505-509.

13. Itoh N, Hanafusa T, Miyazaki A, et al. Mononuclear cell infiltration and its relation to the expression of major histocompatibility complex antigens and adhesion molecules in pancreas biopsy specimens from newly diagnosed insulin-dependent diabetes mellitus patients. J Clin Invest. 1993;92:2313-2322.

14. Huseby ES, Liggitt D, Brabb T, Schnabel B, Ohlen C, Goverman J. A pathogenic role for myelin-specific CD8(+) T cells in a model for multiple sclerosis. J Exp Med. 2001;194:669-676.

15. Babbe $H$, Roers $A$, Waisman $A$, et al. Clonal expansions of $C D 8(+) T$ cells dominate the T cell infiltrate in active multiple sclerosis lesions as shown by micromanipulation and single cell polymerase chain reaction. J Exp Med. 2000;192: 393-404.

16. Ford ML, Evavold BD. Specificity, magnitude, and kinetics of MOG-specific CD8 + T cell responses during experimental autoimmune encephalomyelitis. Eur J Immunol. 2005;35:76-85.

17. Altman JD, Moss PA, Goulder PJ, et al. Phenotypic analysis of antigen-specific T lymphocytes. Science. 1996;274:94-96.

18. Wang B, Maile R, Greenwood R, Collins EJ,
Frelinger JA. Naive CD8 + T cells do not require costimulation for proliferation and differentiation into cytotoxic effector cells. J Immunol. 2000;164 1216-1222.

19. Maile R, Wang B, Schooler W, Meyer A, Collins EJ, Frelinger JA. Antigen-specific modulation of an immune response by in vivo administration of soluble MHC class I tetramers. J Immunol. 2001; 167:3708-3714.

20. Maile R, Siler CA, Kerry SE, Midkiff KE, Collins EJ, Frelinger JA. Peripheral "CD8 tuning" dynamically modulates the size and responsiveness of an antigen-specific T cell pool in vivo. J Immunol. 2005;174:619-627.

21. Yuan RR, Wong P, McDevitt MR, et al. Targeted deletion of T-cell clones using alpha-emitting suicide MHC tetramers. Blood. 2004;104:23972402.

22. Wu YP, McMahon E, Kraine MR, et al. Distribution and characterization of GFP + donor hematogenous cells in twitcher mice after bone marrow transplantation. Am J Pathol. 2000;156:1849 1854.

23. Kerry SE, Maile R, Collins EJ, Frelinger JA. Memory CD8 T cells require CD8 coreceptor engagement for calcium mobilization and proliferation, but not cytokine production. Immunology. 2005; 114:44-52.

24. Kerry SE, Buslepp J, Cramer LA, et al. Interplay between TCR affinity and necessity of coreceptor ligation: high-affinity peptide-MHC/TCR interaction overcomes lack of CD8 engagement. J Immunol. 2003;171:4493-4503.

25. Pircher H, Burki K, Lang R, Hengartner H, Zinkernagel $\mathrm{RM}$. Tolerance induction in double specific T-cell receptor transgenic mice varies with antigen. Nature. 1989;342:559-561

26. Whelan JA, Dunbar PR, Price DA, et al. Specificity of CTL interactions with peptide-MHC class I tetrameric complexes is temperature dependent. J Immunol. 1999;163:4342-4348.

27. Kisielow P, Bluthmann H, Staerz UD, Steinmetz $\mathrm{M}$, von Boehmer $\mathrm{H}$. Tolerance in T-cell-recepto transgenic mice involves deletion of nonmature CD4+8+ thymocytes. Nature. 1988;333:742746

28. von Essen M, Bonefeld CM, Siersma V, et al. Constitutive and ligand-induced TCR degradation. J Immunol. 2004;173:384-393.

29. Cai Z, Kishimoto H, Brunmark A, Jackson MR, Peterson PA, Sprent J. Requirements for peptide induced $T$ cell receptor downregulation on naive CD8+ T cells. J Exp Med. 1997;185:641-651.

30. Alon R, Bayer EA, Wilchek M. Streptavidin contains an RYD sequence which mimics the RGD receptor domain of fibronectin. Biochem Biophys Res Commun. 1990;170:1236-1241.

31. Grayson JM, Laniewski NG, Lanier JG, Ahmed R Mitochondrial potential and reactive oxygen intermediates in antigen-specific CD8 + T cells during viral infection. J Immunol. 2003;170:4745-4751.

32. Bolognesi A, Tazzari PL, Olivieri F, et al. Evaluation of immunotoxins containing single-chain ribosome-inactivating proteins and an anti-CD22 monoclonal antibody (OM124): in vitro and in vivo studies. Br J Haematol. 1998;101:179-188.

33. Thorpe PE, Brown AN, Bremner JA Jr, Foxwell BM, Stirpe F. An immunotoxin composed of monoclonal anti-Thy 1.1 antibody and a ribosome-inactivating protein from Saponaria officinalis: potent antitumor effects in vitro and in vivo. J Natl Cancer Inst. 1985;75:151-159.
34. Stirpe F, Derenzini M, Barbieri L, et al. Hepatotoxicity of immunotoxins made with saporin, a ribosome-inactivating protein from Saponaria officinalis. Virchows Arch B Cell Pathol Incl Mol Pathol. 1987;53:259-271.

35. Bihun C, Bauck L. Basic anatomy, physiology, husbandry and clinical techniques. In: Quesenberry KE, Carpenter JW, eds. Ferrets, Rabbits, and Rodents: Clinical Medicine and Surgery. 2nd ed. St. Louis, MO: Saunders; 2004: 290.

36. Coiffier B, Lepage E, Briere J, et al. CHOP chemotherapy plus rituximab compared with $\mathrm{CHOP}$ alone in elderly patients with diffuse large-B-cell lymphoma. N Engl J Med. 2002;346:235-242.

37. Dillman RO. Radioimmunotherapy of B-cell lymphoma with radiolabelled anti-CD20 monoclonal antibodies. Clin Exp Med. 2006;6:1-12.

38. Leonard JP, Coleman M, Ketas J, et al. Combination antibody therapy with epratuzumab and rituximab in relapsed or refractory non-Hodgkin's lymphoma. J Clin Oncol. 2005;23:5044-5051.

39. Montillo M, Tedeschi A, Miqueleiz S, et al. Alemtuzumab as consolidation after a response to fludarabine is effective in purging residual disease in patients with chronic lymphocytic leukemia. $\mathrm{J}$ Clin Oncol. 2006;24:2337-2342.

40. Eisenbarth GS, Srikanta S, Jackson R, et al. Antithymocyte globulin and prednisone immunotherapy of recent onset type 1 diabetes mellitus. Diabetes Res. 1985;2:271-276.

41. Coles AJ, Wing MG, Molyneux P, et al. Monoclonal antibody treatment exposes three mechanisms underlying the clinical course of multiple sclerosis. Ann Neurol. 1999;46:296-304.

42. Bacigalupo A. Antithymocyte globulin for prevention of graft-versus-host disease. Curr Opin $\mathrm{He}-$ matol. 2005;12:457-462.

43. Juliusson G, Theorin N, Karlsson K, Frodin U, Malm C. Subcutaneous alemtuzumab vs ATG in adjusted conditioning for allogeneic transplantation: influence of Campath dose on lymphoid recovery, mixed chimerism and survival. Bone Marrow Transplant. 2006;37:503-510.

44. Tazzari PL, Polito L, Bolognesi A, et al. Immunotoxins containing recombinant anti-CTLA-4 single-chain fragment variable antibodies and saporin: in vitro results and in vivo effects in an acute rejection model. J Immunol. 2001;167: 4222-4229.

45. Tazzari PL, Bolognesi A, De Totero D, et al. BB10 (anti-CD25)-saporin immunotoxin: a possible tool in graft-versus-host disease treatment. Transplantation. 1992;54:351-356.

46. Han B, Serra P, Amrani A, et al. Prevention of diabetes by manipulation of anti-IGRP autoimmunity: high efficiency of a low-affinity peptide. Nat Med. 2005; 11:645-652.

47. Daniels MA, Devine L, Miller JD, et al. CD8 binding to MHC class I molecules is influenced by $\mathrm{T}$ cell maturation and glycosylation. Immunity. 2001;15:1051-1061.

48. Kessler BM, Bassanini P, Cerottini JC, Luescher IF. Effects of epitope modification on T cell receptor-ligand binding and antigen recognition by seven $\mathrm{H}-2 \mathrm{Kd}$-restricted cytotoxic T lymphocyte clones specific for a photoreactive peptide derivative. J Exp Med. 1997;185:629-640.

49. Holmberg K, Mariathasan S, Ohteki T, Ohashi PS, Gascoigne NR. TCR binding kinetics measured with $\mathrm{MHC}$ class I tetramers reveal a positive selecting peptide with relatively high affinity for TCR. J Immunol. 2003;171:2427-2434. 